Article

\title{
Biocontrol and Plant-Growth-Promoting Traits of Talaromyces apiculatus and Clonostachys rosea Consortium against Ganoderma Basal Stem Rot Disease of Oil Palm
}

\author{
Yit Kheng Goh ${ }^{1, *} \mathbb{0}$, Nurul Fadhilah Marzuki ${ }^{1}$, Tuan Nur Fatihah Tuan Pa ${ }^{1}$, \\ Teik-Khiang Goh ${ }^{1,2}{ }^{(D}$, Zeng Seng Kee ${ }^{1}$, You Keng Goh ${ }^{1}$, Mohd Termizi Yusof ${ }^{3}$, \\ Vladimir Vujanovic ${ }^{4}$ and Kah Joo Goh ${ }^{1}$ (D) \\ 1 Advanced Agriecological Research Sdn Bhd, Kota Damansara, Petaling Jaya 47810, Malaysia; \\ nf91fadh@gmail.com (N.F.M.); tuanfatihah@gmail.com (T.N.F.T.P.); \\ tkgohmagic2005@yahoo.com.hk (T.-K.G.); keezs@aarsb.com.my (Z.S.K.); gohyk@aarsb.com.my (Y.K.G.); \\ gohkj@aarsb.com.my (K.J.G.) \\ 2 Department of Plant Medicine, National Chiayi University, Chiayi City 60004, Taiwan \\ 3 Department of Microbiology, Faculty of Biotechnology and Biomolecular Sciences, University Putra \\ Malaysia, Serdang 43400, Malaysia; mohdtermizi@upm.edu.my \\ 4 Department of Food and Bioproduct Sciences, University of Saskatchewan, Saskatoon, SK S7N 5A8, Canada; \\ vlv699@mail.usask.ca \\ * Correspondence: gohykheng@aarsb.com.my; Tel.: +603-6151-7928
}

Received: 29 June 2020; Accepted: 24 July 2020; Published: 28 July 2020

check for updates

\begin{abstract}
Basal stem rot (BSR) disease caused by Ganoderma boninense basidiomycetous fungus is the most economically important disease in oil palms in South East Asia. Unfortunately, there is no single most effective control measure available. Tremendous efforts have been directed in incorporation of environmentally friendly biocontrol approaches in minimizing BSR disease. This study investigated the performance of two potential biocontrol agents (BCAs), AAT0115 and AAB0114 strains recovered from oil palm on suppression of BSR in planta, and also assessed their plant-growth-promoting (PGP) performance. ITS rRNA-sequence phylogeny discriminated the two ascomycetous Talaromyces apiculatus (Ta) AT0115 and Clonostachys rosea (Cr) AAB0114 biocontrol species with PGP characteristics. In vitro studies have demonstrated both $\mathrm{Ta}$ and $\mathrm{Cr}$ are capable of reducing linear mycelial growth of G. boninense. Inoculation of individual $\mathrm{Cr}$ and $\mathrm{Ta}-$ as well as $\mathrm{Cr}+\mathrm{Ta}$ consortium-induced a significant increment in leaf area and bole girth of oil-palm seedlings five months post-inoculation (MPI) under nursery conditions. At five months post-inoculation, shoot and root biomass, and nutrient contents (nitrogen, phosphorus, potassium, calcium, magnesium and boron) were significantly higher in Ta-inoculated seedlings compared to control treated with non-Ta-inoculated maize. Chlorophyll and carotenoids contents in rapidly growing oil-palm seedlings challenged with $\mathrm{Cr}$, Ta or a combination of both were not negatively affected. $\mathrm{Cr}$, Ta and $\mathrm{Cr}+\mathrm{Ta}$ consortium treated seedlings had $4.9-60 \%$ BSR disease reduction compared to the untreated control. Co-inoculation of $\mathrm{Cr}$ and Ta resulted in increased BSR control efficiencies by 18-26\% (compared with Cr only) and 48-55\% (compared with Ta only). Collectively, $\mathrm{Cr}$ and $\mathrm{Ta}$, either individually or in consortium showed potential as BSR biocontrol agents while also possess PGP traits in oil palm.
\end{abstract}

Keywords: antagonistic fungus; ascomycete; biologic control; mycoparasite; Ganoderma boninense; plant growth 


\section{Introduction}

Basal Stem Rot (BSR) in oil palm (Elaeis guineensis Jacq.) is one of the most devastating oil palm diseases in South East Asia (SEA), particularly in Malaysia and Indonesia-and to a lesser extent in other countries in Africa, Papua New Guinea and Thailand [1]. Ganoderma white rot disease is estimated to inflict economic losses as high as USD 500 million annually in Malaysia [2,3]. Ganoderma diseases caused yield losses in oil palms through reducing healthy productive standing palms and decreasing their economic lifespan [4,5]. BSR causes infection and decay of the root system and the lower stem, leading to various common foliar symptoms such as frond fracture, yellowing and smaller young fronds [5,6]. Formation of basidiocarps on the lower stem and in severe cases, toppling of the stem are some of the key signs as well. Among the commonly isolated Ganoderma spp. from oil palm with BSR disease, Ganoderma boninense Pat. was the most widespread and pathogenic species in oil palm plantations compared to the less pathogenic counterparts, namely Ganoderma zonatum Murrill and Ganoderma miniatocinctum Steyaert [7].

Different cultural and physical methods, namely soil mounding, surgery, trenching, ploughing and harrowing, fallowing and removal of basidiocarps, as well as chemical means had been investigated. Unfortunately, none has been effective for controlling BSR disease [2]. Lack of reproducible and highly reliable early detection methods further makes the control of Ganoderma disease even more difficult [2]. Cultural and physical disease management approaches are generally laborious, costly and time-consuming [2,8,9]. Some of the commonly tested commercial cultural practices, namely sanitation through felling and chipping of diseased palms, as well as deboling of the infected root bole during replanting or at the existing planting-with the aim of minimizing the amount of infected tissues buried or left in the soil-may reduce disease infection rate, if done properly [2,8]. The efficacy of using commercially available fungicides has yet been proven [8] and also hindered by a lack of reliable early detection methods. Furthermore, the potential deleterious effects on the environment due to chemical pesticides are still arguable. Therefore, this has encouraged more research for effective environment-friendly biocontrol approaches [10].

Incorporation of two or more biocontrol candidates-either a combination of fungal-fungal, fungal-bacterial or bacterial-bacterial isolates - in managing various important plant diseases has long been adopted. They also showed better efficacy over the use of a single beneficial microbe [10-14]. Application of fungal consortia of more than one biologic control agents (BCAs) was suggested as a useful approach to minimize the variation of BCAs effectiveness in suppressing diseases. Furthermore, this approach is also capable of maximizing the efficacy of the beneficial plant-growth-promoting (PGP) microbes under diverse, uncontrollable and dynamic environmental conditions [12,15-18]. Introduction of more than one BCA into the BSR pathosystem of oil palms to manage G. boninense is not uncommon. Various previous studies using different microbial consortia-in particular a few endophytic bacterial isolates, arbuscular mycorrhizal fungi and bacteria, Trichoderma spp. and bacteria or Penicillium spp. and bacteria-has been conducted under controlled conditions and showed the potential of reducing Ganoderma disease infection and improving oil-palm growth [19-22].

In the last decade, only a handful of Ganoderma-associated fungi have been isolated and identified, including the ascomycetous Cladobotryum semicirculare G.R.W. Arnold, R. Kirschner \& Chee J. Chen from Ganoderma lingzhi Sheng H. Wu, Y. Cao \& Y.C. Dai [23] and G. boninense [24], Scytalidium ganodermophthorum Kang, Sigler, Y.W. Lee \& S.H. Yun parasitizing Ganoderma lucidum (Curtis) P. Karst. [25], S. parasiticum Y-Kheng Goh, Goh, Y.K. Goh, K.J. Goh from G. boninense [26] and a Phlebiopsis species-parasitizing Ganoderma philippii (Bres. \& Henn. Ex Sacc.) Bres. [27]. Some of the Ganoderma-associated fungi isolated and described from Ganoderma applanatum (Pers.) Pat. and Ganoderma carnosum Pat. in 1980s and 1990s were outlined by Helfer [28]. Cladobotryum semicirculare was observed to suppress G. boninense in in vitro assays [24]. Similarly, Scytalidium parasiticum-a potential necrotrophic mycoparasite - was found to reduce oil palm BSR disease incidence and severity in nursery experiments [29]. Agustini and co-workers [27] reported the ability of Phlebiopsis species in 
parasitizing and reducing the viability of G. philippii in in vitro assays and they suggested that it is a potential biocontrol agent for Eucalyptus pellita F. Muell root rot.

In this study, two Ganoderma-associated fungicolous AAT0115 and AAB0114 isolates were isolated from rubber-wood blocks (RWB) pre-colonized with G. boninense and oil-palm trunk tissues infected with G. boninense, respectively. Based on $\beta$-tubulin and ITS sequences, the AAT0115 and AAB0114 were identified as Talaromyces apiculatus (Ta) Samson, N. Yilmaz \& Frisvad and Clonostachys rosea (Preuss) Mussat (Cr), respectively. Both Talaromyces and Clonostachys are among the most important fungal chitinolytic antagonists used as BCAs, with some PGP activities in agriculture crops [30,31]. Hence, we studied Ta-AAT0115 and Cr-AAB0114 abilities to suppress Ganoderma boninense growth, reduce Ganoderma disease incidence and severity in a nursery oil palm experiment, either applied individually or in combination. Furthermore, the capabilities of $\mathrm{Cr}$ or $\mathrm{Ta}$ - either applied as a consortium or individually for improving oil-palm growth, nutrient status and chlorophyll contents-were also investigated under nursery environments.

\section{Materials and Methods}

\subsection{Fungal Isolation and Maintenance}

Rubber-wood blocks (RWB) with the size of $3 \mathrm{~cm} \times 3 \mathrm{~cm} \times 3 \mathrm{~cm}$ were prepared and artificially inoculated with Ganoderma boninense G14 according to Kok et al. [32]. Mesh bags with inoculated RWB were transferred and buried in a coastal-soil, Blenheim series (Typic Quartzipsamments) (obtained from Blenheim Estate at coordinates: $3^{\circ} 55^{\prime} 39.40^{\prime \prime} \mathrm{N} ; 100^{\circ} 48^{\prime} 48.58^{\prime \prime} \mathrm{E}$ ), and further incubated for an additional month in the dark at $24{ }^{\circ} \mathrm{C}$. Mycelial masses of AAT0115 proliferated on RWB pre-colonized with G. boninense were collected using flame-sterilized needle under a dissecting microscope and plated onto malt extract agar (MEA) (Difco, Becton Dickinson Diagnostics, Sparks, Maryland, USA) supplemented with antibiotic (100 $\mu \mathrm{g} / \mathrm{L}$ of streptomycin sulfate and $12 \mathrm{mg} / \mathrm{L}$ kanamycin sulfate) (Sigma-Aldrich, St. Louis, Missouri, USA). AAB0114 isolate was isolated from oil-palm trunk tissues infected by G. boninense: Diseased oil-palm trunk tissues were collected from Stothard Estate (coordinates: $5^{\circ} 35^{\prime} 43.37^{\prime \prime} \mathrm{N} ; 100^{\circ} 42^{\prime} 58.41^{\prime \prime}$ E) and incubated on Ganoderma-selective medium (GSM) [33,34] for a month in the dark at $24{ }^{\circ} \mathrm{C}$. AAB0114 proliferated on the diseased tissues on GSM, and was transferred onto MEA supplemented with antibiotics. Pure cultures of AAT0115 (Ta) and AAB0114 $(\mathrm{Cr})$ were maintained on MEA prior to DNA extraction, in vitro and in planta (nursery) experiments. AAT0115 and AAB0114 inoculants used for in planta (nursery) experiments were prepared according to Goh et al. [29]: One cm plugs of AAT0115 or AAB0114 mycelial culture were inoculated onto $50 \mathrm{~g}$ of sterilized maize and incubated for 4 weeks at $24^{\circ} \mathrm{C}$ in the dark. Maize was presoaked twice with double-distilled water, air-dried overnight, and autoclaved at $121^{\circ} \mathrm{C}$ for $20 \mathrm{~min}$ prior to inoculation. The inoculated 4-week-old maize seeds were air-dried under laminar flow overnight, prior to blending into powder using a Waring ${ }^{\circledR}$ laboratory blender.

\subsection{Molecular and Phylogenetic Analyses of AAT0115 and AAB0114}

AAT0115 and AAB0114 were cultured on MEA and incubated at $24{ }^{\circ} \mathrm{C}$ for a week prior to DNA extraction. Genomic DNA was extracted with the DNeasy plant mini kit (Qiagen, Hilden, Germany). ITS (Internal transcribed spacer) fragments were amplified using ITS1 F/ITS4 primer set (ITS1 F-5'-CTTGGTCATTTAGAGGAAGTAA-3' and ITS4-5'-TCCTCCGCTTATTGATATGC-3') [35] for both AAT0115 and AAB0114 isolates. Polymerase chain reaction (PCR) was performed according to Vujanovic and Goh [36] with Qiagen Top Taq PCR core kits (Qiagen, Hilden, Germany) and PCR conditions for ITS were outlined previously [37]. Beta-tubulin (BenA) region (one of the commonly used regions for identification of Talaromyces/Penicillium genera) [38] was amplified with primer set Bt2a (5'-GGTAACCAAATCGGTGCTGCTTTC-3') and Bt2b (5'-ACCCTCAGTGTAGTGACCCTTGGC-3') and similar PCR conditions were adopted (Glass and Donaldson 1995) for AAT0115 isolate only. All PCR products were purified using QIAquick PCR purification kit (Qiagen, Hilden, Germany) and 
purified PCR products were sent to Genomics (Taipei, Taiwan) for sequencing. The ITS sequences obtained from AAT0115 and AAB0114 were submitted to GenBank under the accession Nos.: KY421922 and MG754415, respectively. Furthermore, beta-tubulin sequence for AAT0115 was deposited as KY421924. Sequences of ITS and beta-tubulin gene from the current study and a few previous studies were retrieved from GenBank and were aligned using Clustal W [39] and edited in MEGA version 6 [40]. Maximum likelihood (ML) analyses were carried out using MEGA version 6 software with the following settings: Tamura-Neil model; bootstrap analyses of 1000 repetitions; and nearest-neighbor-interchange ML heuristic method [40]. Phylogenetic trees were generated with sequences illustrating bootstrap values higher than 50\%. Trees based on ITS sequences for AAT0115 and AAB0114 were rooted with Trichocoma paradoxa CBS788.83 (JN899398) and Isaria japonica BCC2821 (EU828662) sequences, respectively. Furthermore, tree based on beta-tubulin sequences for AAT0115 was rooted with T. paradoxa CBS788.83 (KF984556).

\subsection{Dual-Culture Bioassays}

Four G. boninense isolates, namely, G10, G14, G8 and G12 with different pathogenicity levels (determined in previous study) [32] were selected to inoculate with Ta and $\mathrm{Cr}$ in dual-culture assays to assess their capability in suppressing the growth of four selected G. boninense isolates on MEA. Ta or Cr mycelial plugs (10-mm diameter) were excised using a 10-mm diameter cork-borer from actively growing colonies and placed $2 \mathrm{~cm}$ from each of the G. boninense isolates in Petri dishes containing MEA. Linear mycelial growths $(\mathrm{mm})$ of the four $G$. boninense isolates from the respective co-culture pairings in five replications were measured and recorded on alternate day for 2 weeks.

\subsection{Plant-Growth-Promoting Analysis and Determination of Leaf Chlorophyll Contents}

Germinated oil-palm seeds (Dumpy Yangambi Avros DxP) (purchased from Applied Agricultural Resources Sdn. Bhd, Selangor, Malaysia) were planted, maintained and fertilized (drenched weekly using Bayfolan ${ }^{\circledR}$ foliar fertilizer with N:P:K-11:8:6 at the rate recommended by manufacturer) as described by Kok et al. [32] for 2 months. Plants were watered twice per day (approximately 45 min per session). The experiment was carried out under a 50\% polyethylene shading net. Two-month-old seedlings with similar uniformity were selected and transferred to $38 \times 51 \mathrm{~cm}$ black polythene bags filled with Bungor series soil (Typic paleudult) (fine sandy clay) (soil chemical parameters-Table S1) to determine the effects of AAT0115 (Ta) and AAB0114 (Cr) -applied either individually or in combination-on the growth of oil-palm seedlings and leaf chlorophyll contents. Descriptions of all the treatments and controls adopted in this experiment are outlined in Table 1. During transplanting, two-month-old seedlings were inoculated with $50 \mathrm{~g}$ of blended Cr (AAB0114) or Ta (AAT0115) inoculant at the base of the stem bole and the roots, for Cr50 or Ta50 treatments. For the treatment with combination of $\mathrm{Cr}$ and Ta inoculant at $25 \mathrm{~g}$ rates, twenty-five grams of blended $\mathrm{Cr}$ and Ta inoculants (total of $50 \mathrm{~g}$ of inoculants), respectively, were applied for treatment of Cr25+Ta25. In control 1, the seedlings were inoculated with $50 \mathrm{~g}$ of blended uninoculated maize inoculum (Ctrl 1), whereas, in control 2, there was no application of inoculated or uninoculated maize (Ctrl 2). Three treatments and two controls with 6 replicates for each treatment in randomized complete block design (RCBD) were used in the nursery study. Height $(\mathrm{cm})(\mathrm{H})$, leaf area $\left(\mathrm{cm}^{2}\right)(\mathrm{LA})$ and girth of the bole (diameter) $(\mathrm{cm})(\mathrm{G})$ of the seedlings were measured, calculated and recorded at 1, 3 and 5 months post-inoculation (MPI), following the nondestructive techniques reported previously [41-44]. Leaf chlorophyll and carotenoid contents were extracted and assayed according to the procedures outlined by Sim et al. [45], with some minor modifications: Six leaf discs (leaf tip, middle and base -2 from each respective regions) were collected at $5 \mathrm{MPI}$ using a conventional paper puncher and weighed prior to placing in $500 \mu \mathrm{L} 80 \%$ acetone before storing in the dark at $4{ }^{\circ} \mathrm{C}$ overnight. Extraction was repeated on the same leaves and the supernatants were pooled and used for analysis. The extractants were measured using UV-Vis Spectrophotometer at $470 \mathrm{~nm}, 647 \mathrm{~nm}$ and $663 \mathrm{~nm}$. Chlorophyll a, chlorophyll b and carotenoid contents were calculated using the formulae proposed by Lichtenthaler and Buschmann [46]: 
(a) chlorophyll a $(\mu \mathrm{g} / \mathrm{mL})=12.25 \mathrm{~A}_{663}-2.79 \mathrm{~A}_{647} ;$ (b) chlorophyll b $(\mu \mathrm{g} / \mathrm{mL})=21.50 \mathrm{~A}_{647}-5.10 \mathrm{~A}_{663}$; and $(\mathrm{c})$ carotenoid $(\mu \mathrm{g} / \mathrm{mL})=\left(1000 \mathrm{~A}_{470}-1.82\right.$ chlorophyll a -85.02 chlorophyll $(\mathrm{b}) / 198$.

Table 1. Treatments and controls with their respective descriptions adopted for plant-growth-promoting experiment using AAB0114 (Cr) and AAT0115 (Ta) isolates.

\begin{tabular}{cc}
\hline Treatments & Descriptions \\
\hline Cr50 & Inoculation with 50 g of blended AAB0114 (Cr) inoculant \\
Ta50 & Inoculation with 50 g of blended AAT0115 (Ta) inoculant \\
Cr25+Ta25 & Inoculation with consortium of 25 g Cr and 25 g Ta inoculant \\
Ctrl 1 (control 1) & Application of uninoculated blended maize (50 g) only \\
Ctrl 2 (control 2) & Without uninoculated blended maize \\
\hline
\end{tabular}

\subsection{Plant Nutrient Analyses}

Above-ground (shoot: leaf, rachis and bole) and below-ground (root) samples of all seedlings were harvested at $5 \mathrm{MPI}$ and fresh weights were recorded for all three treatments and two controls, namely +Cr50, +Ta50, +Cr25+Ta25, control 1 (uninoculated blended maize) and control 2 (with only seedling) (Table 1). Shoot and root samples were rinsed and washed with sterilized distilled water. Shoot (leaf, rachis and bole) and root samples were oven-dried at $70{ }^{\circ} \mathrm{C}$ until constant weight was achieved, and the dry weights were recorded. Oven-dried shoot and root samples were ground and sent to Applied Agricultural Resources Sdn Bhd (AAR) Chemistry Analytical Laboratory (Selangor, Malaysia) for macro- and micronutrient analysis. The shoot and root samples were analyzed for nitrogen $(\mathrm{N})$, phosphorus $(\mathrm{P})$, potassium $(\mathrm{K})$, calcium $(\mathrm{Ca})$, magnesium $(\mathrm{Mg})$ and boron $(\mathrm{B})$ according to methods adopted by Sharifuddin et al. [47].

\subsection{Nursery Biocontrol Experiment}

Two-month-old oil-palm seedlings (Dumpy Yangambi Avros DxP) were used to assess the efficacy of Ta and $\mathrm{Cr}$, either applied individually or in combination, in reducing G. boninense (G10 isolate) disease incidence (DI) and severity in the nursery. The oil-palm seedlings were prepared by growing germinated seeds for two months in $15 \times 21 \mathrm{~cm}$ black polythene bags filled with cocopeat prior to artificial inoculation with Ganoderma-inoculated RWB and transplanted to $38 \times 51 \mathrm{~cm}$ polyethene bags filled with Bungor series soil. Plants were watered twice per day (approximately $45 \mathrm{~min}$ per session) and experiment was carried out under $50 \%$ polyethylene shading net. Artificial inoculation of RWB at the size of $6 \mathrm{~cm} \times 6 \mathrm{~cm} \times 6 \mathrm{~cm}$ with G. boninense (G10 isolate) was prepared according to [32]. Similar treatments and controls adopted for plant-growth-promoting study (Table 1) were used in the biocontrol experiment with one additional treatment and some minor modifications. During transplanting, Ganoderma-inoculated (G10 + Cr50, G10 + Ta50 and G10 + Cr25 + Ta25) or uninoculated RWB (-G10-Cr-Ta) were placed below the 2-month-old seedlings. Inoculum of BCAs was applied together with the Ganoderma inoculum during the transplanting. Fifty grams of blended $\mathrm{Cr}$ or $\mathrm{Ta}$ inoculant was applied to the base of the stem bole and the roots for G10 + Cr50 and G10 + Ta50 treatments. For the treatment with both $\mathrm{Cr}$ and Ta inoculants at 25-g rates, twenty-five grams of blended $\mathrm{Cr}$ and Ta inoculants (total of $50 \mathrm{~g}$ of inoculants), respectively, were applied for $\mathrm{G} 10+\mathrm{Cr} 25+$ Ta25-treatment. In the control, seedlings were challenged with uninoculated RWB and $50 \mathrm{~g}$ of blended uninoculated maize inoculum (-G10-Cr-Ta). Four treatments and one control with 10 replicates for each treatment in RCBD were used in the nursery study. Observations and scoring for the appearance of Ganoderma infection symptoms or signs were recorded at monthly intervals up to 5 MPI.

DI and disease severity index (DSI) were calculated based on the formulae reported earlier by Campbell and Madden [48] and Sapak et al. [49]. Formula for DI = (number of seedlings identified as diseased / number of seedlings per treatment set $) \times 100 \%$. DSI was calculated using the following formula: DSI $=$ (number of seedlings in the rating $\times$ rating number or disease class value) $/$ (total number of seedlings assessed $\times$ highest rating or disease class value). Disease classes adopted for DSI calculation were described in [32]. Percent of disease reduction was determined based on the formula 
given by [49]. The area under the disease progress curve (AUDPC) based on DSI from 1 to 5 MPI was calculated with the formula proposed by Sinko and Piepho [50].

\subsection{Statistical Analyses}

Difference in means for linear mycelial growth of the selected G. boninense isolates inoculated with or without AAT0115 and AAB0114 on MEA, as well as means separation of three different vegetative growth measurement (VGM) parameters on 3- and 5-MPI for the respective treatments (without Ganoderma inoculum) were analyzed using ANOVA-Fisher's test with SPSS version 16.0 (SPSS, Inc., Chicago, IL, USA). Means for the major nutrients analyzed in shoot and root for the five treatments without $G$. boninense-as well as means of DSI for oil-palm seedlings challenged with $G$. boninense and inoculation of biocontrol agent(s) at 3- and 5-MPI-were not normally distributed under Shapiro-Wilk test and were transformed where necessary using arcsine-square root transformation prior to ANOVA-Fisher's test (Minitab version16, Minitab, Inc., State College, PA, USA). Boxplots were generated with the R ggplot2 package [51]. Principal component analyses (PCA) were performed using vegetative growth parameters (H, LA and G) recorded at 3- and 5-MPI, shoot and root major nutrient analyses (N, P, K, Ca, Mg and B), as well as shoot and root dry weights extracted from plant-growth-promoting experiment (recorded for three treatments and two controls: Cr50, Ta50, Cr25+Ta25, Ctrl 1 and Ctrl 2) with RStudio [52].

\section{Results}

\subsection{Molecular Identification of AAT0115 and AAB0114 Isolates}

Two ascomycetous isolates, namely AAT0115 (Figure 1A) and AAB0114 (Figure 1B), were recovered from $G$. boninense-colonized RWB (as a bait) and oil-palm trunk tissues infected by G. boninense, respectively. Both AAT0115 and AAB0114 were constantly isolated and cultured from G. boninense-colonized RWB and G. boninense-infected palm trunk tissues, respectively, over 2 to 3 isolation attempts to isolate G. boninense. Based on the NCBI nucleotide database BLAST search using ITS sequences, the closest hits for AAT0115 and AAB0114 were Talaromyces aculeatus $(100 \%$ percent identity toMH316150 with $100 \%$ query coverage) and Clonostachys rosea ( $99.6 \%$ percent identity to MK203790 with 100\% query coverage), respectively. Sequence alignments and ML analysis at $1000 \times$ bootstrap repetitions for the ITS sequences placed AAT0115 close together with T. apiculatus but separated from T. aculeatus (Figure 2A) and AAB0114 within the clade as two other C. rosea isolates (Figure 2B). AAT0115 had biverticilliate conidiophores and globose rough to echinulate conidia (Figure S1A-C), with no ascomata. Whereas, AAB0114 had relatively complex conidiophores with mainly biverticilliate, hypaline and smooth primary conidiophores and penicillate-like secondary conidiophores (Figure S1D-F). AAB0114 also produced hyaline, distally broadly rounded and slightly curved conidia. In order to differentiate AAT0115 from T. aculeatus, beta-tubulin sequence was obtained and sequence alignment and ML analysis at 1000x bootstrap repetitions with beta-tubulin sequences placed AAT0115 close together with T. apiculatus (Figure 3).
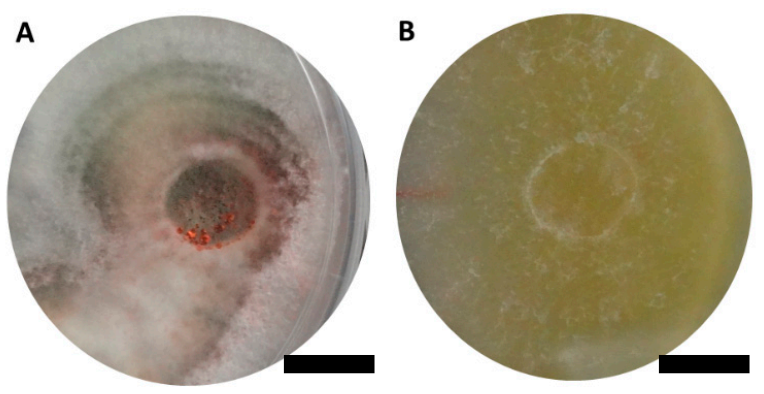

Figure 1. Colony appearances of (A) Talaromyces apiculatus (Ta) AAT0115 and (B) Clonostachys rosea (Cr) AAB0114 on malt extract agar incubated for 7 days. Scale bar: $10 \mathrm{~mm}$. 


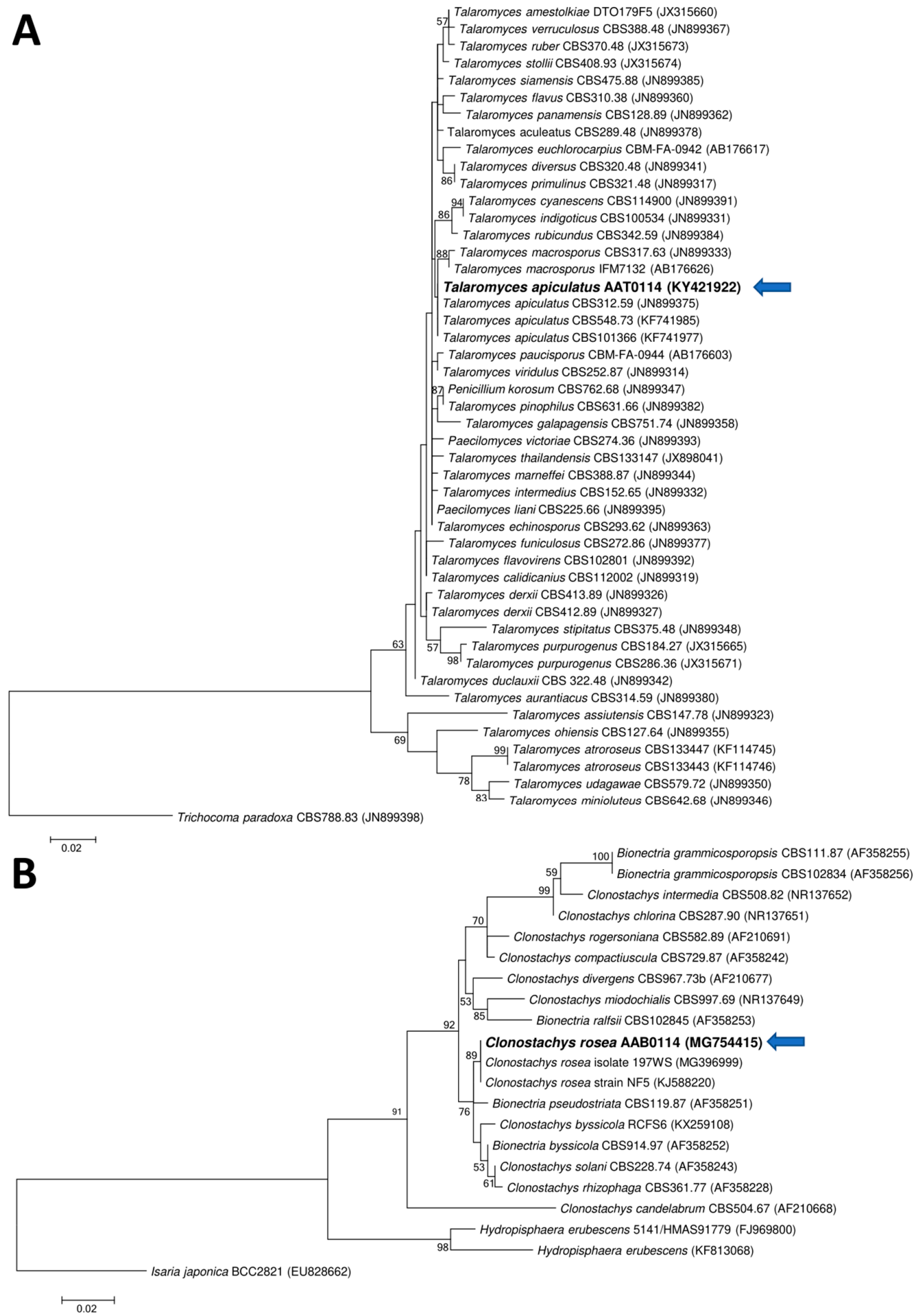

Figure 2. Phylogenetic relationship of (A) AAT0115 or (B) AAB0114 and their closely related isolates/species based on the internal transcribed spacer (ITS) rDNA sequences and positions of currently studied ascomycetes (in bold) (arrow). Two fungal taxa-namely Trichocoma paradoxa CBS788.83 (JN899398) and Isaria japonica BCC2821 (EU828662)—were used as the outgroups for the respective phylogenetic trees generated through maximum likelihood approach. Bootstrap values of $\geq 50 \%$ from 1000 bootstrap repetitions are shown for the corresponding branches. Scale bars indicate estimation of 0.02 substitutions per nucleotide position for the branch lengths. 


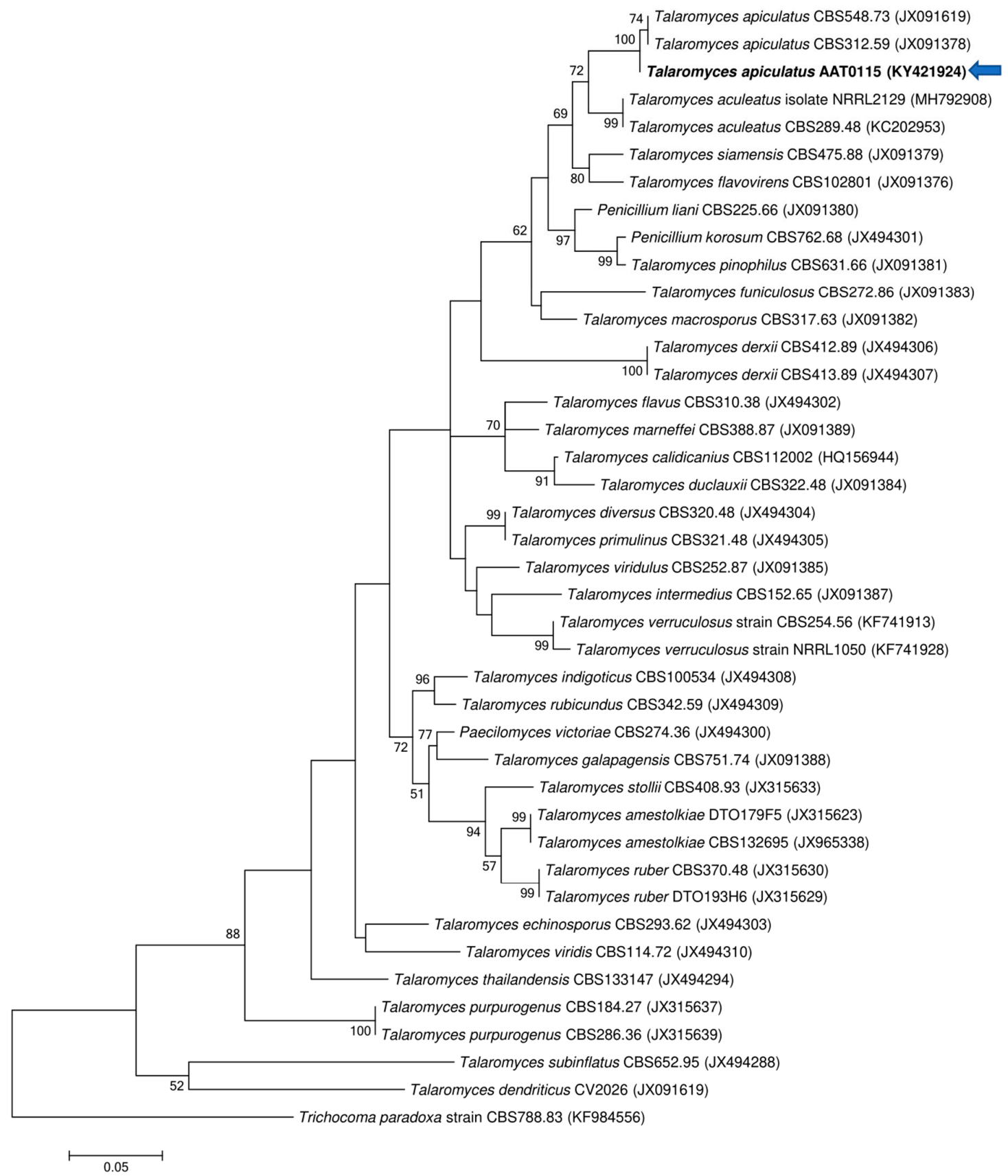

Figure 3. Phylogenetic relationship of AAT0115 and its closely related species based on beta-tubulin (BenA) sequences and position of the AAT0115 (in bold) (arrow). Trichocoma paradoxa CBS788.83 (KF984556) was used as the outgroup for the phylogenetic tree generated through maximum likelihood approach. Bootstrap values $\geq 50 \%$ from 1000 bootstrap repetitions are shown for the corresponding branches. Scale bars indicate estimation of 0.05 substitutions per nucleotide position for the branch lengths.

\subsection{In Vitro Ganoderma Boninense Growth Suppression}

Talaromyces apiculatus AAT0115 (Ta) and Clonostachys rosea AAB0114 (Cr) significantly suppressed the growth of all four pathogenic G. boninense isolates in dual-culture assays regardless of the pathogenicity status of G. boninense (Table 2). Ganoderma linear growth suppression by $\mathrm{Cr}$ at 2 weeks post-inoculation (WPI) was comparable to Ta. However, Cr was more aggressive at the later time points, being able to degrade G. boninense mycelia and hyphae or cause "clearing zone" on the dual-culture 
assays approximately after 3-4 WPI (Figure S2A-D). Initiation of chlamydospore-like structures (Figure S3A) and cell degradation (Figure S3B) of G. boninense mycelia were observed at the interaction zone with $\mathrm{Cr}$ on dual-culture and water agar (WA) slide assays. Barrage lines and mycelia at the interaction zone were degraded and the clearing zone formed at 4 WPI (Figure S2A-D). In contrast, barrage line at the confrontation zone between Ta and G. boninense was denser at 4 WPI (Figure S2E-H). In WA slide assay, Ta produced various biotrophic contact structures, namely haustoria-like and peg-like organs, on G. boninense cells (Figure S3E,F,H). Internal penetration and growth within $G$. boninense mycelia by Ta were also observed (Figure S3D,G). Based on preliminary observation, both $\mathrm{Cr}$ and Ta could potentially be the antagonist and biotrophic parasitic fungi, respectively.

Table 2. Reduction of linear mycelial growth of four Ganoderma boninense isolates by Talaromyces apiculatus AAT0115 and Clonostachys rosea AAB0114 on malt extract agar (MEA) 14 days after inoculation (DAI).

\begin{tabular}{ccccc}
\hline $\begin{array}{c}\text { Ganoderma boninense } \\
\text { Isolates }\end{array}$ & $\begin{array}{c}\text { Pathogenicity } \\
\text { Level } \S\end{array}$ & Treatment & \multicolumn{2}{c}{$\begin{array}{c}\text { Linear Mycelial Growth of } \\
\text { Ganoderma Colony (mm) }{ }^{\mathbf{a}}\end{array}$} \\
\cline { 4 - 5 } & Low & Control & $44.17(1.77) \mathrm{c}$ & $44.17(1.77) \mathrm{c}$ \\
G. boniense isolate G8 & With Ta or Cr & $20.47(1.57) \mathrm{e}$ & $22.73(1.10) \mathrm{e}$ \\
G. boninense isolate G10 & High & Control & $53.30(0.25) \mathrm{a}$ & $53.30(0.25) \mathrm{a}$ \\
& High & With Ta or Cr & $26.53(0.20) \mathrm{d}$ & $32.47(0.87) \mathrm{d}$ \\
G. boninense isolate G14 & Control & $53.13(0.33) \mathrm{a}$ & $53.13(0.33) \mathrm{a}$ \\
& & With Ta or Cr & $25.47(2.01) \mathrm{d}$ & $31.07(2.11) \mathrm{d}$ \\
G. boninense isolate G12 & Moderate & Control & $48.03(1.36) \mathrm{b}$ & $48.03(1.36) \mathrm{b}$ \\
& & With Ta or Cr & $25.60(0.84) \mathrm{d}$ & $24.73(2.08) \mathrm{e}$ \\
\hline
\end{tabular}

\footnotetext{
Abbreviations: Ta: Talaromyces apiculatus AAT0115 and Cr: Clonostachys rosea AAB0114. § Pathogenicity levels were based on disease scorings, namely disease incidence and disease severity index of oil-palm seedlings, reported in the previous study for the respective G. boninense isolates [32]. ${ }^{a}$ Linear mycelial growth of Ganoderma colony $(\mathrm{mm})$ challenged with or without (control) T. apiculatus and C. rosea in dual-culture assays on MEA were analyzed separately for the respective $\mathrm{Ta}$ and $\mathrm{Cr}$ columns; means of linear Ganoderma colony's growth (mm) within individual $\mathrm{Ta}$ and $\mathrm{Cr}$ columns for all the four $\mathrm{G}$. boninense isolates followed by the same letter are not significantly different at $p=0.05$ after ANOVA-Fisher's test. Numbers in the bracket are the standard errors for the respective means.
}

\subsection{Plant-Growth-Promoting Abilities of Clonostachys rosea and Talaromyces apiculatus}

Inoculation of $\mathrm{Cr}$ and Ta individually or in consortium significantly improved oil-palm seedling leaf area, girth diameter of the bole and height compared to the controls (with or without uninoculated maize) at 5 months post-inoculation (MPI) (Figure 4A-C). Furthermore, the height of oil-palm seedlings inoculated with only Ta was significantly taller compared to the controls (Ctrl 1 and Ctrl 2) (Figure 4B). Similarly, root and shoot dry weights of the seedlings inoculated with only Ta were significantly higher compared to the controls at 5 MPI (Figure 5). At the end of the experiment (5 MPI), root and shoot samples were analyzed for the pertinent major and minor nutrients. Treatments with either $\mathrm{Cr}$, Ta or both showed better root and shoot nutrient levels, in particular N, P, K, Ca, Mg and B, compared to control 1 (uninoculated maize only)(Figure 6A-F). Treatment with only Ta demonstrated significantly greater root and shoot nutrients compared to the controls as well (Figure 6A-F). PCA plots, based on first three components, were able to explain approximately $89 \%$ of the selected variables (Figure 7A,B). Early plant vegetative growth parameters (at 3-MPI) were positively associated with Cr inoculation (Figure 7B) while Ta inoculation illustrated better correlation with plant nutrient status (Figure 7A,B). Consortium of $\mathrm{Cr}$ and Ta improved both plant growth and plant nutrient status (Figure 7B). All the treatments inclusive of the controls had similar chlorophyll ( $a$ and b) and carotenoids contents (Figure 8). 

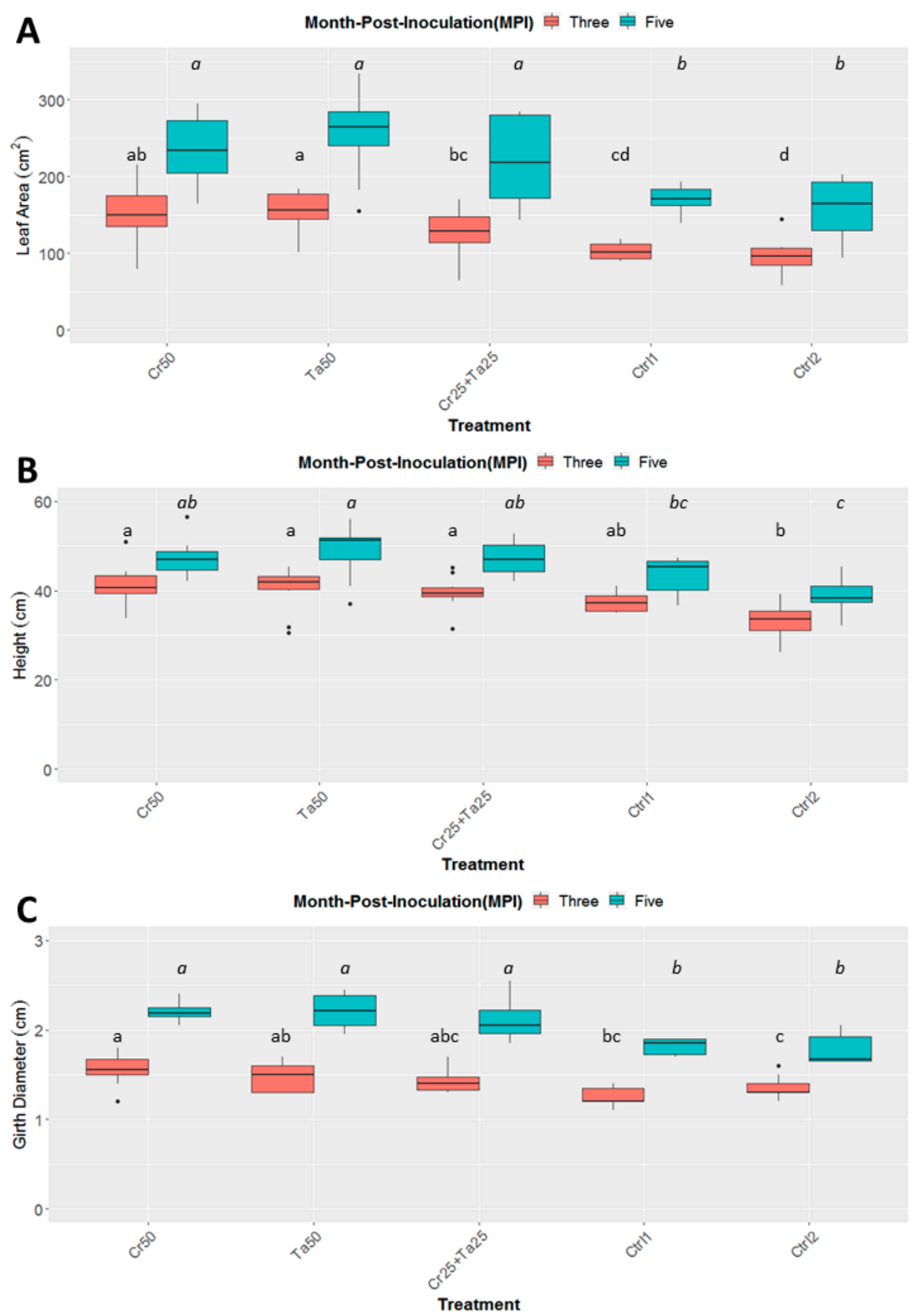

Figure 4. Effects of $\mathrm{Ta}$ and $\mathrm{Cr}$, either applied individually or in consortium on the development and growth of oil-palm seedlings, namely leaf area (A), height (B), and diameter of the bole girth (C), 3 and 5 months post-inoculation (MPI). Treatments abbreviations: $\mathrm{Cr} 50$-inoculated with $50 \mathrm{~g}$ of $C$. rosea AAB0114 ( $\mathrm{Cr}$ ); Ta50 - inoculated with $50 \mathrm{~g}$ of T. apiculatus AAT0115 (Ta); Cr25 + Ta25-inoculated with $25 \mathrm{~g}$ of $\mathrm{Cr}$ and $25 \mathrm{~g}$ of $\mathrm{Ta}$; control 1 -only the uninoculated blended maize was applied; and control 2 -without the uninoculated blended maize. Means of the three different vegetative growth parameters (VGM) at two separate recording time points (3 and $5 \mathrm{MPI}$ ) were analyzed separately. Means with the same letters for the all five treatments within 3 or 5 MPI for the respective VGM parameters were not significantly different with ANOVA-Fisher at $p=0.05$. Numbers presented in the figures are untransformed means. 


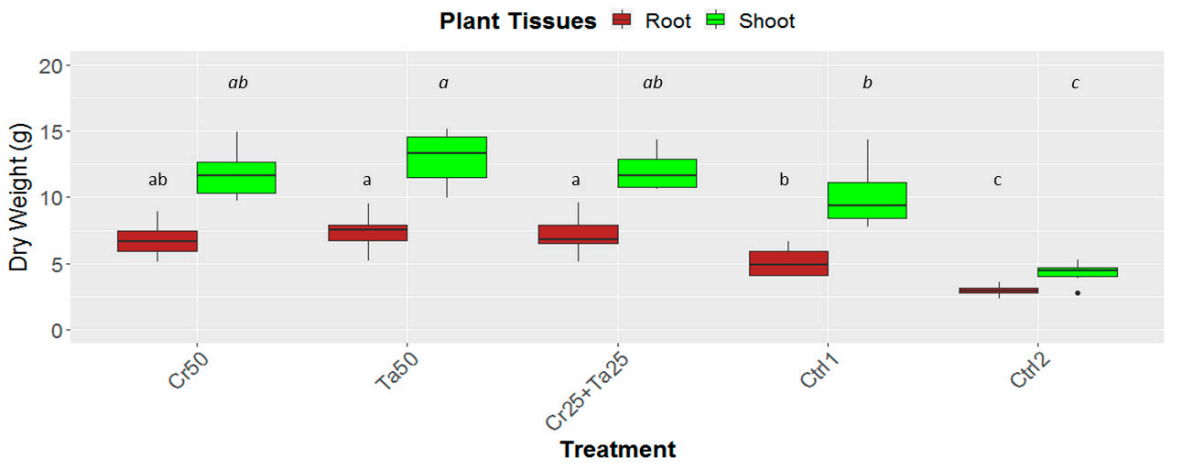

Figure 5. Effects of $\mathrm{Ta}$ and $\mathrm{Cr}$, either applied individually or in consortium on the root and shoot dry weight of oil-palm seedlings at 5 months post-inoculation (MPI). Treatments abbreviations: Cr50-inoculated with $50 \mathrm{~g}$ of $\mathrm{C}$. rosea AAB0114 (Cr); Ta50-inoculated with $50 \mathrm{~g}$ of T. apiculatus AAT0115 (Ta); Cr25+Ta25-inoculated with $25 \mathrm{~g}$ of $\mathrm{Cr}$ and $25 \mathrm{~g}$ of $\mathrm{Ta}$; control 1 -only the uninoculated blended maize was applied; and control 2-without the uninoculated blended maize. Means of the root and shoot dry weights were analyzed separately. Means with the same letters for the all five treatments the respective root and shoot dry weights were not significantly different with ANOVA-Fisher at $p=0.05$.
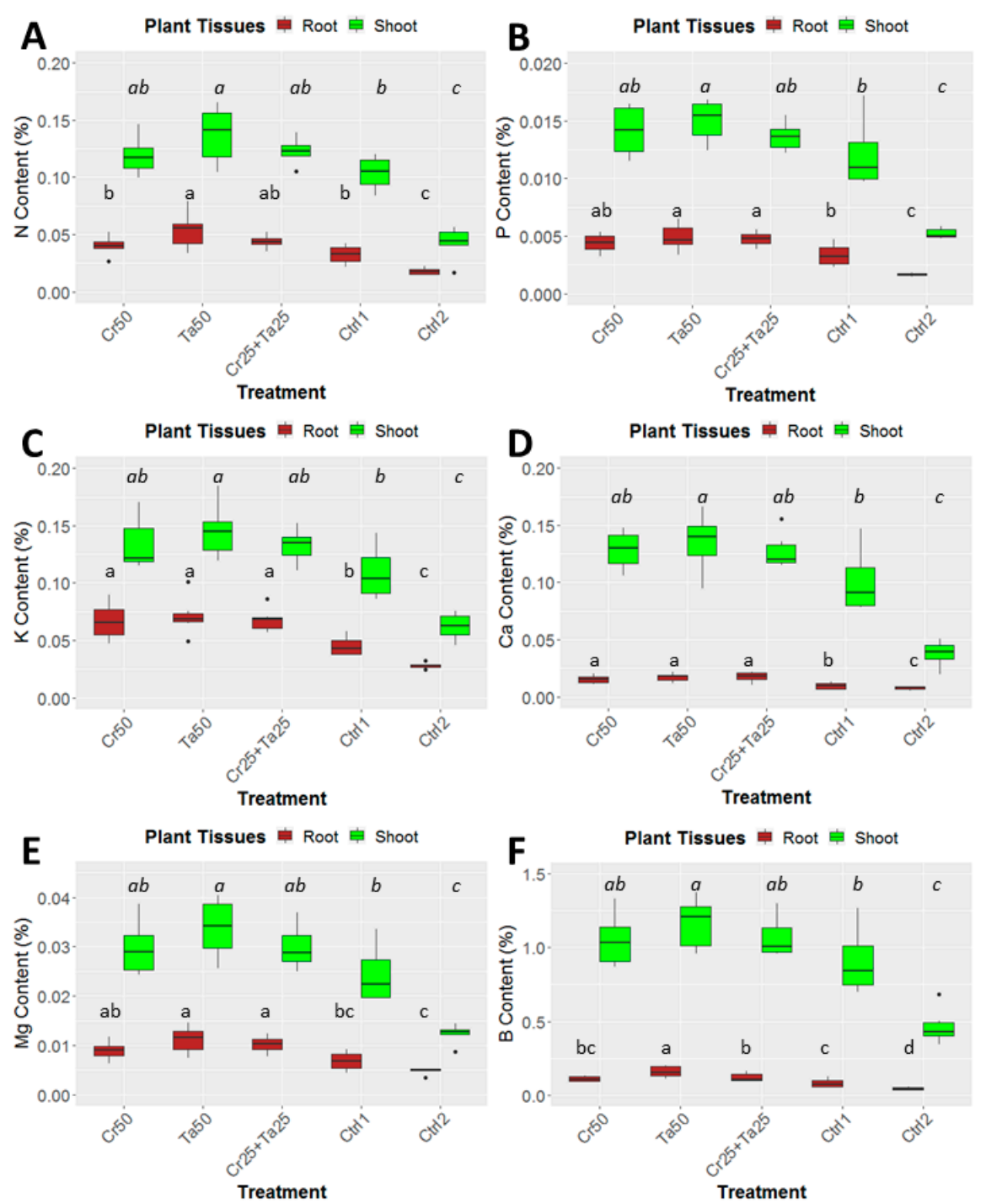

Figure 6. Effects of $\mathrm{Ta}$ and $\mathrm{Cr}$, either applied individually or in consortium on the shoot and root nutrient contents in oil-palm seedlings at 5 months post-inoculation (MPI) and nutrients analyzed were 
(A) Nitrogen or N content, (B) phosphorus or P content, (C) potassium or K content, (D) magnesium or Mg content, (E) Calcium or Ca content and (F) Boron or B concentration. Treatments abbreviations: Cr50-inoculated with $50 \mathrm{~g}$ of $\mathrm{C}$. rosea AAB0114 (Cr); Ta50-inoculated with $50 \mathrm{~g}$ of T. apiculatus AAT0115 (Ta); Cr25 + Ta25-inoculated with $25 \mathrm{~g}$ of $\mathrm{Cr}$ and $25 \mathrm{~g}$ of $\mathrm{Ta}$; control 1-only the uninoculated blended maize was applied; and control 2-without the uninoculated blended maize. Means of the three different vegetative growth parameters (VGM) at two separate recording time points ( 3 and $5 \mathrm{MPI})$ were analyzed separately. Means with the same letters for the all five treatments within 3 or 5 MPI for the respective VGM parameters were not significantly different with ANOVA-Fisher at $p=0.05$.

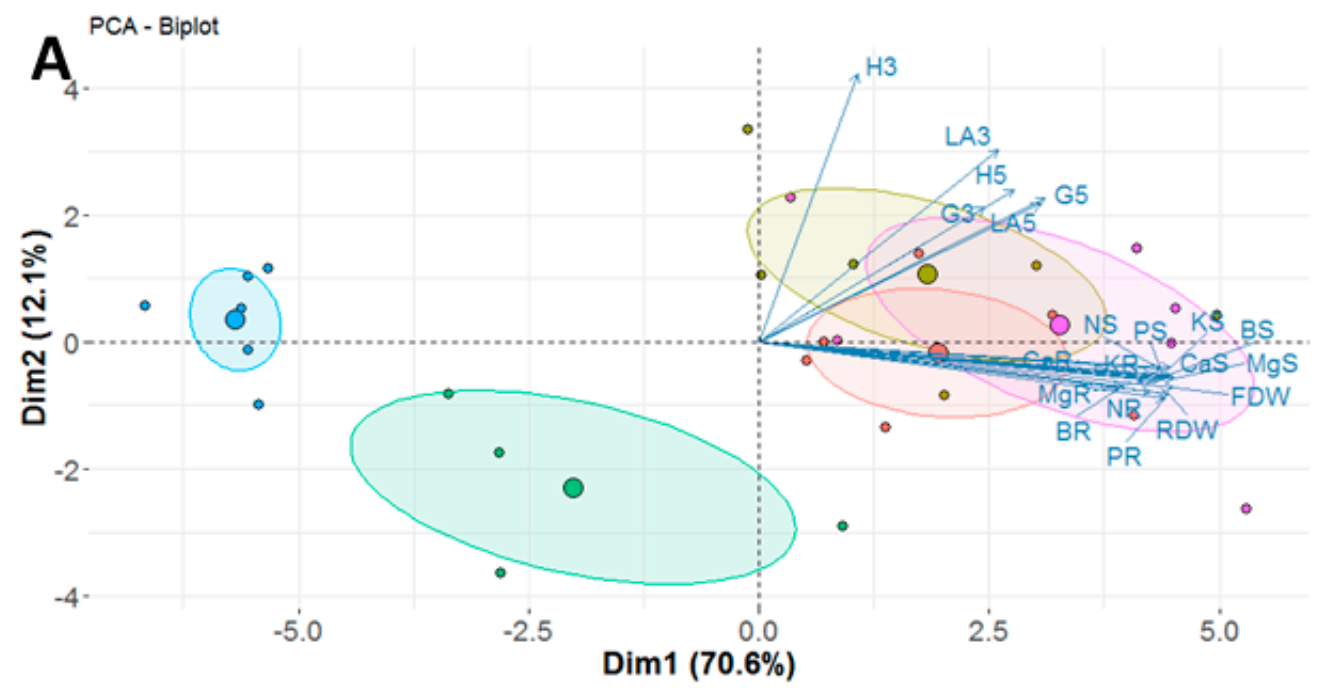

Treatments

- $\mathrm{Cr} 25+\mathrm{Ta} 25$

- $\mathrm{Cr} 50$

으 Ctrl1

C $\operatorname{ctr} 12$

- $\mathrm{Ta} 50$

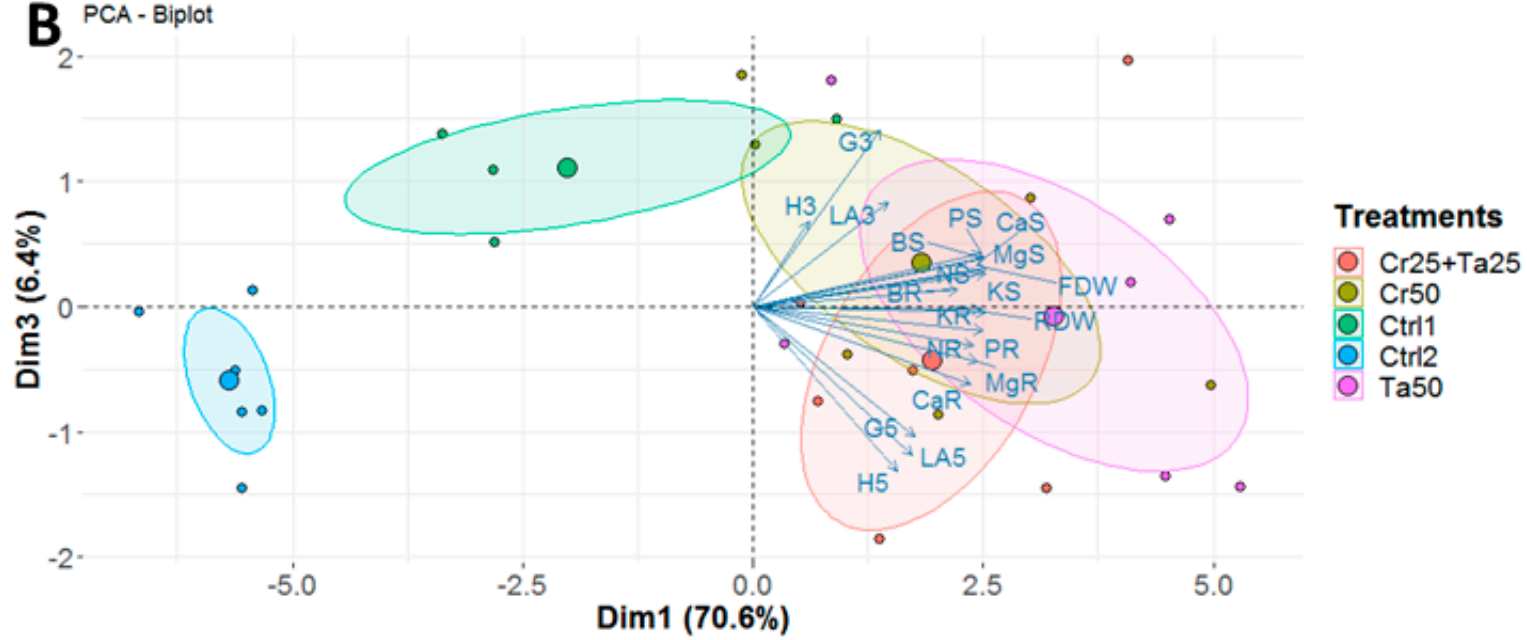

Figure 7. Principal component analysis (PCA) plots generated using (A) first and second dimensions and (B) first and third dimensions, based on various plant vegetative growth measurements and plant nutrient analyses for three treatments (Cr50, Ta50 and Cr25 + Ta25) and two controls (Ctrl 1 and Ctrl 2). Abbreviations: H, G and LA—height, girth and leaf area at 3- or 5-MPI; FDW-shoot dry weight; RDW-root dry weight; N, P, K, Ca, Mg and B-nitrogen, phosphorus, potassium, calcium, magnesium and boron for shoot (S) and root (R). 


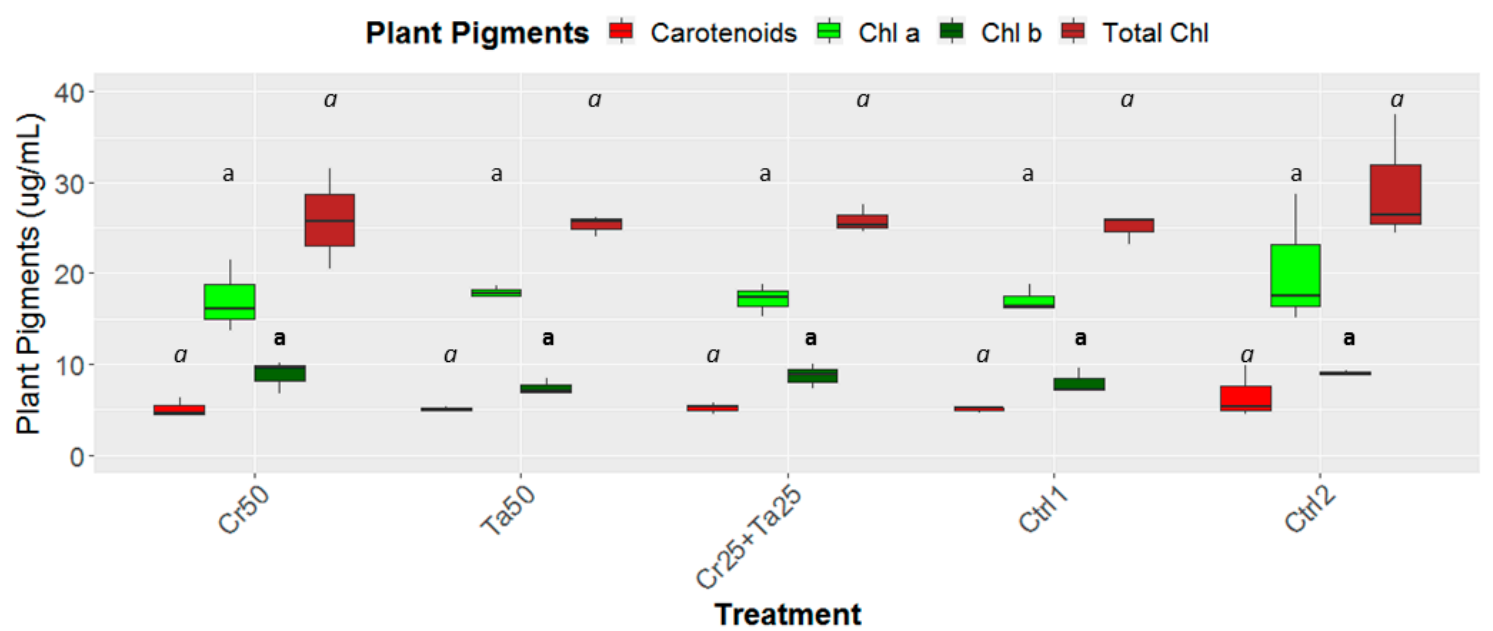

Figure 8. Effects of $\mathrm{Ta}$ and $\mathrm{Cr}$, either applied individually or in consortium on the leaf chlorophyll as well as carotenoid contents and total chlorophylls for oil-palm seedlings at 5 months post-inoculation (MPI). Treatments abbreviations: $\mathrm{Cr} 50$-inoculated with $50 \mathrm{~g}$ of $\mathrm{C}$. rosea AAB0114 ( $\mathrm{Cr})$; Ta50 —inoculated with $50 \mathrm{~g}$ of T. apiculatus AAT0115 (Ta); Cr25+Ta25-inoculated with $25 \mathrm{~g}$ of $\mathrm{Cr}$ and $25 \mathrm{~g}$ of $\mathrm{Ta}$; Control 1 -only the uninoculated blended maize was applied; and Control 2-without the uninoculated blended maize. Means of the four different plant pigments, namely chlorophyll a (Chl a), chlorophyll b (Chl b), carotenoids and total chlorophylls (Total Chl) were analyzed separately. Means with the same letters for all five treatments for the respective plant pigments were not significantly different with ANOVA-Fisher at $P=0.05$.

3.4. Efficacy of Clonostachys rosea and Talaromyces apiculatus in controlling Ganoderma Basal Stem Rot Disease of Oil Palm

In nursery experiment, combinations of $\mathrm{Cr}$ and $\mathrm{Ta}$ (at the doses of $25 \mathrm{~g} \mathrm{Cr}+25 \mathrm{~g}$ Ta and $50 \mathrm{~g}$ $\mathrm{Cr}+50 \mathrm{~g} \mathrm{Ta}$ ) reduced disease incidence (DI) to 50-60\% from 100\% (control) (Table 3). Cr and Ta consortium also contributed to $52 \%$ to $60 \%$ disease reduction (DR) (derived from area under disease progression curve based on disease severity indices) compared to the treatments with either $\mathrm{Cr}$ or $\mathrm{Ta}$ alone. Increased in the inoculum quantity of $\mathrm{Cr}$ and $\mathrm{Ta}$ (consortium) gave better Ganoderma disease reduction in oil palms. Application of $\mathrm{Cr}$ and Ta consortium at higher rate (50 g Cr and $50 \mathrm{~g} \mathrm{Ta}$ ) significantly reduced both disease severity index (DSI) and area under disease progres curve (AUDPC) (Table 3). 
Table 3. Effects of Ta and Cr, either applied individually or in combination on the development of oil palm BSR by Ganoderma boninense.

\begin{tabular}{|c|c|c|c|c|c|c|c|c|}
\hline \multirow{3}{*}{ Treatment ${ }^{a}$} & \multicolumn{8}{|c|}{ Disease Census } \\
\hline & \multicolumn{3}{|c|}{ DI $(\%)$ on MPI ${ }^{b}$} & \multicolumn{2}{|c|}{ DSI $(\%)^{c}$ on MPI ${ }^{b}$} & \multirow{2}{*}{$\frac{\operatorname{AUDPC}(\%)^{\mathrm{d}}}{5}$} & \multicolumn{2}{|c|}{$\operatorname{DR}(\%){ }^{e}$} \\
\hline & 3 & 4 & 5 & 3 & 4 & & & \\
\hline +G10-Cr-Ta & 40 & 70 & 100 & $16.67(7.86) \mathrm{a}$ & $40.00(10.90) \mathrm{a}$ & $75.00(7.14) \mathrm{a}$ & $54.17 \mathrm{a}$ & - \\
\hline +G10+Cr50 & 10 & 50 & 80 & $5.00(5.00) \mathrm{ab}$ & $36.67(14.00)$ a & $61.67(13.20) \mathrm{ab}$ & $35.84 \mathrm{ab}$ & 33.84 \\
\hline$+\mathrm{G} 10+\mathrm{Ta} 50$ & 30 & 60 & 80 & $16.67(9.30) \mathrm{ab}$ & $35.00(12.50) \mathrm{a}$ & 70.00 (11.90) a & $51.67 \mathrm{a}$ & 4.62 \\
\hline$+\mathrm{G} 10+\mathrm{Cr} 25+\mathrm{Ta} 25$ & 0 & 20 & 60 & $0 \mathrm{~b}$ & $11.67(8.62) \mathrm{a}$ & $51.67(14.20) \mathrm{ab}$ & $25.8 \mathrm{ab}$ & 52.37 \\
\hline$+\mathrm{G} 10+\mathrm{Cr} 50+\mathrm{Ta} 50$ & 10 & 20 & 50 & $5.00(5.00) \mathrm{ab}$ & 18.33 (12.30) a & $33.33(12.90) b$ & $21.67 \mathrm{~b}$ & 60 \\
\hline
\end{tabular}

a Treatments: +G10-Cr-Ta—with RWB inoculated with G. boninense isolate G10 (G10) only with $50 \mathrm{~g}$ of uninoculated ground maize; +G10 + Cr50-with RWB inoculated with G10 and 50 g of C. rosea AAB0114 (Cr); +G10 + Ta50-with RWB inoculated with G10 and $50 \mathrm{~g}$ of T. apiculatus AAT0115 (Ta); +G10 + Cr25 + Ta25-with RWB inoculated with G10, $25 \mathrm{~g}$ of Cr and $25 \mathrm{~g}$ of $\mathrm{Ta}$; and +G10 + Cr50 + Ta50-with RWB inoculated with G10, $50 \mathrm{~g}$ of $\mathrm{Cr}$ and $50 \mathrm{~g}$ of Ta. ${ }^{\mathrm{b}}$ MPI refers to months post-inoculation. ${ }^{\mathrm{c}}$ Means of DSI at three separate months post-inoculation ( 3,4 and 5 MPI) were analyzed separately. Means within each column of MPI followed by the same letter are not significantly different at $p=0.05$ after ANOVA-Fisher's test. ${ }^{d}$ AUDPC refers to area under disease progress curve. Means within the column of AUDPC followed by the same letter are not significantly different at $p=0.05$ after ANOVA-Fisher's test. ${ }^{\text {e }}$ DR refers to percent disease reduction in percent of AUDPC. Numbers presented in the figures are untransformed means. 


\section{Discussion}

A combination of two fungicolous T. apiculatus and C. rosea (Ascomycetes) demonstrated biocontrol activity against G. boninense (Basidiomycete) BSR disease and also plant-growth-promoting (PGP) effect on oil-palm seedlings. Using RWB pre-inoculated with G. boninense (as bait) technique and G. boninense-infected oil-palm trunk tissues collected from the field, Talaromyces apiculatus AAT0115 and Clonostachys rosea AAB0114, respectively, were isolated. Microscopic observation also showed that T. apiculatus AAT0115 produced biverticilliate conidiophores and globose rough to echinulate conidia (Figure S1A-C). There was no sexual fruiting bodies observed. These morphologic features were also reported in T. aculeatus and Talaromyces verruculosus species [38]. Further, C. rosea AAB0114 produced biverticilliate or verticillium-like primary conidiophores, penicillate-like secondary conidiophores and slightly curved and distally broadly rounded conidia (Figure S1D,F). These morphologic characteristics produced by C. rosea AAB0114 were also described previously by Schroers et al. [53].

In vitro bioassays demonstrated that both T. apiculatus and C. rosea were capable of suppressing four tested pathogenic G. boninense isolates (Table 2). Despite lower G. boninense growth suppression at two weeks post-inoculation, $\mathrm{Cr}$ began to degrade G. boninense mycelia at 3-4WPI (Figure S1A-D). This phenomenon has contributed to the induction of chlamydospore-like resting structures, cell degradation or lysing and vacuolation in G. boninense mycelia (Figure S3A,B). Formation of chlamydospore-like survival resting organs, swollen structures and degradation or lysing of host mycelial cells were some of the common effects due to antibiosis mechanism (caused by highly potent lytic enzymes or secondary metabolites) at the confrontation points with bacterial or fungal antagonistic biocontrol agents [54-56]. Antagonistic C. rosea was also reported as potential biocontrol agent for other diseases [57] as it carries in its genome gene clusters which encode for the synthesis of antifungal polyketide (e.g., clonorosein A-D by C. rosea) that is pivotal for fungal-fungal antagonism [58]. Furthermore, C. rosea also upregulated cr-nag1 (highly similar to n-acetyl-beta-d-glucosaminidase) gene during confrontation with Fusarium culmorum and indicated the production of chitin-hydrolyzing agents [59]. Upregulation of genes responsible for production of antifungal and cell wall degrading agents may play imperative role in suppressing G. boninense growth. On the other hand, T. apiculatus produced a few common haustoria- and peg-like biotrophic contact organs, as well as established intracellular penetration into G. boninense host (Figure S3D-H). These contact structures were also reported in other biotrophic mycoparasites of Fusarium species [36,60,61]. To-date, there is little information related to the potential biotrophic mycoparasitic association between Ta and G. boninense. Two other Talaromyces species, in particular T. pinophilus and T. flavus had been reported previously as potential mycoparasite candidates [54]. Furthermore, a few other Talaromyces species, namely T. helices, T. indigoticus, T. rotundus and T. wortmannii showed mycelial growth inhibitory effects toward various fungal pathogens (Fusarium, Colletotrichum, Phytophthora, Rhizoctonia and Sclerotium species) [62]. In a few previous studies, T. apiculatus was reported to produce a list of fungal extrolites (macrocyclic polyactones) in which five of the compounds, namely NG-012, BK-223B, BK-223C, 15G256 3 and $15 G 256 \alpha-2$ were found to have antifungal activity [38,63-65].

In this study, leaf area, bole-girth diameter and root dry weight of the oil-palm seedlings were improved through inoculation of $\mathrm{Cr}$, Ta or consortium compared to the uninoculated controls (Figure 4, Figure 5 and Figure S4). To the best of our knowledge, there is very little information related to the plant-growth-promoting effect of T. apiculatus in oil palm. This is the first study on the potential plant-growth-promoting effects by Ta or in combination with $\mathrm{Cr}$ in oil palm. In a few studies, Talaromyces species, namely T. wortmannii, T. flavus and T. pinophilus promoted the growth of cabbage, cotton and potato and rice seedlings, respectively $[31,66,67]$. PCA plots also illustrated the positive relationship between $\mathrm{Cr}$ inoculation and early oil-palm growth (at 3-MPI) (Figure 7B). Growth-promoting effects by C. rosea AAB0114 in oil-palm seedlings were in accordance with a few previous studies. Clonostachys rosea IK726 isolate inoculation contributed to an increase of 5-15\% in barley shoot dry weight [68]. Endophytic C. rosea strain 88-710 was observed to improve the growth of flower plants and cucumbers as well [69]. In our study, oil-palm seedlings inoculated with T. apiculatus demonstrated significant 
higher shoot and root N, P, K, Ca, Mg and B compared to the control with uninoculated maize (Figure 6). Inoculation of Ta was positively correlated with better plant nutrient status (Figure 7A,B). This agrees with a previous study that showed T. pinophilus inoculation enhanced nutrients uptake, in particular N, P and K, by pomegranate (Punica granatum L.) [70]. Phosphate solubilizing T. pinophilus was also found to improve soil availability of $\mathrm{P}$ by $1.4-15.4 \%$ and increase $\mathrm{P}$ content in soybean plants by 1.3-8.9\% [71]. A more detailed study on nutrient-solubilizing or -uptake capabilities by $\mathrm{Cr}$ and $\mathrm{Ta}$ could shed some lights on the improvement of nutrient contents recorded. Increase in both vegetative growth parameters did not negatively affect chlorophyll (chlorophyll a and b) and carotenoids contents. This could also be due to improvement in the leaf nutrient status and nutrient uptake.

In the nursery experiment, the $\mathrm{Cr}$ and Ta consortium at highest tested rate $(50 \mathrm{~g} \mathrm{Cr}+50 \mathrm{~g} \mathrm{Ta})$ demonstrated greater Ganoderma disease reduction compared to treatments with single inoculation-either $\mathrm{Cr}$ or Ta (Table 3). Higher dosage of $\mathrm{Cr}$ and Ta consortium should also be evaluated in the future studies to determine whether the efficacy of disease controlling will be maintained as observed in the treatment with consortium of $50 \mathrm{~g} \mathrm{Cr}+50 \mathrm{~g}$ Ta. The enhanced control could be the cumulative results of a combination of antagonistic/destructive parasitism by $\mathrm{Cr}$ (distance active) and biotrophic parasitism by Ta (intracellular) mechanisms, improvement in plant growth and health, as well as better nutrient status. Furthermore, improved disease control by $\mathrm{Cr}$ and Ta could be also due to induction of defense-related mechanisms and genes in the plants toward G. boninense infection. Inoculation of C. rosea biocontrol agent was reported to induce disease resistance toward Botrytis cinerea and Fusarium oxysporum, respectively, in tomato plants [72,73]. In a separate study with Talaromyces wortmannii, this fungus was found to produce $\beta$-caryophyllene (terpenoid-like volatiles) with plant-growth-promoting and also disease resistance induction properties [66]. Additionally, combination of multiple potential biologic control agents (BCAs) with different mechanisms were reported to enhance the efficacy of the BCAs, minimize the inconsistency of biocontrol efficacy and improve durability of biocontrol $[12,17,74]$. Moreover, the ability of fungi in ameliorating a series of biotic and abiotic elements, predominantly through augmentation of plant's nutrient uptake, could also be one of the important mechanisms adopted by biocontrol agents in ensuring a better palm health for better disease control [53,75]. In order to determine the full potential of both $\mathrm{Cr}$ and Ta in promoting growth of oil palms and also Ganoderma disease suppression, it is essential to carry out similar experiments in field tests. In addition, it is also pivotal to combine formulation tests with field experiments to optimize the amount of BCAs inoculum and frequency of application required in the perennial oil palm ecosystem for the BCAs to reach their full potential in reducing Ganoderma BSR disease.

\section{Conclusions}

Together with development of highly precise early Ganoderma BSR detection techniques and availability of potential disease tolerant/resistant oil palm materials, biologic control represents a publicly acceptable, eco-friendly or green approach for reducing Ganoderma BSR disease in oil palm. Under in vitro conditions, both C. rosea AAB0114 and T. apiculatus AAT0115 were capable of suppressing the growth of four selected pathogenic G. boninense isolates. Furthermore, a combination/consortium of aggressive antagonistic C. rosea and intracellular biotrophic mycoparasitic T. apiculatus BCAs isolated from Ganoderma-infected substrates could improve plant growth and nutrients status and reduce the incidence and severity of oil palm Ganoderma BSR disease. Although, reduction in Ganoderma BSR disease scorings was not high, Talaromyces apiculatus if applied singly could enhance significantly greater plant growth and biomass. Application of the C. rosea and T. apiculatus consortium or only T. apiculatus could be the potential mycofungicide and biofertilizer products, respectively, in the future for improving oil-palm growth and reducing Ganoderma BSR disease.

Supplementary Materials: The following are available online at http://www.mdpi.com/2076-2607/8/8/1138/s1, Figure S1: Morphologic appearances of conidiophores and conidia for Talaromyces apiculatus (A-C) and Clonostachys rosea (D-F). Scale bars are $100 \mu \mathrm{m}$ (for A,B \& D-F) and $10 \mu \mathrm{m}$ (for C), Figure S2: Dual-culture assays between Talaromyces apiculatus (Ta) (A-D) or Clonostachys rosea $(\mathrm{Cr})(\mathrm{E}-\mathrm{H})$ and Ganoderma boninense $(\mathrm{Gb})$ on MEA at 2- (A,B 
\& E,F) and 4-WPI (C,D \& G-H) for top- (A, C, E, \& G) and bottom-view (B, D, F, \& H) of the plates. Arrows (red) showed the clearing zone (of $\mathrm{Gb}$ mycelial mat) by $\mathrm{Cr}$ at 4-WPI, Figure S3: Observations and various structures or organs formed at the interaction zones between Clonostachys rosea $(\mathrm{A}, \mathrm{B})$ or Talaromyces apiculatus $(\mathrm{D}-\mathrm{H})$ and Ganoderma boninense (C: morphology of G. boniense in control plate) on water agar slide culture. Arrows and abbreviations for the respective structures or organs: clamp connection (CC) and chlamydopore-like (Ch) structures formed by G. boninense, cell wall degradation or lysing (DL) in G. boninense by C. rosea and various biotrophic contact structures/organs produce by T. apiculatus - intracellular penetration (IP) and haustorial-like (HL). Scale bars are $100 \mu \mathrm{m}$, Figure S4: Growth and heights of oil-palm seedlings challenged with various treatments at the end of the experiment. Treatments abbreviations: Cr50-inoculated with $50 \mathrm{~g}$ of $\mathrm{C}$. rosea AAB0114 (Cr); Ta50-inoculated with $50 \mathrm{~g}$ of T. apiculatus AAT0115 (Ta); Cr25 + Ta25-inoculated with $25 \mathrm{~g}$ of $\mathrm{Cr}$ and $25 \mathrm{~g}$ of Ta; control 1-only the uninoculated blended maize was applied; and control 2-without the uninoculated blended maize. Red line showed the height comparison between inoculated and uninoculated (controls) seedlings, Table S1: Soil chemical parameters for Bungor soil series used for nursery experiments.

Author Contributions: Conceptualization, Y.K.G. (Yit Kheng Goh), N.F.M., Y.K.G. (You Keng Goh) and K.J.G.; methodology, Y.K.G. (Yit Kheng Goh), N.F.M. and T.N.F.T.P.; validation, Y.K.G. (Yit Kheng Goh), N.F.M., T.N.F.T.P., T.-K.G. and V.V.; formal analysis, Y.K.G. (Yit Kheng Goh), N.F.M. and Z.S.K.; investigation, Y.K.G. (Yit Kheng Goh), N.F.M. and T.N.F.T.P.; data curation, N.F.M. and T.N.F.T.P.; writing-original draft preparation, Y.K.G. (Yit Kheng Goh), N.F.M. and M.T.Y.; writing—review and editing, Y.K.G. (Yit Kheng Goh), N.F.M., T.-K.G., V.V., M.T.Y., Y.K.G. (You Keng Goh) and K.J.G.; visualization, Y.K.G. (Yit Kheng Goh), N.F.M. and Z.S.K.; funding acquisition, Y.K.G. (You Keng Goh) and K.J.G. All authors have read and agreed to the published version of the manuscript.

Funding: This research received no external funding.

Acknowledgments: The authors would like to thank the invaluable technical assistances from Ismail Hasim, Muhammad Al Quayyum Hassan Basri, Rahaizul Rakman, Nortasnim Abu Hassan Kusaheri and Muhd Nazirul Rosli. We would like to thank Wong Wei Chee, Tan Swee Sian, Tung Hun Jiat and Ong Cu Ean for assistances and discussion on the topic of molecular works. The authors would like to thank Lim Choon Kiat and Petronella for discussion on chlorophyll and plant nutrient analyses, respectively. We would also like to thank our Principals, Boustead Plantation Berhad and Kuala Lumpur Kepong Berhad for their permission to publish these data and for their financial backing given to the research activities leading to this article.

Conflicts of Interest: The authors declare no conflicts of interest.

\section{References}

1. Idris, A.; Kushairi, A.; Ismail, S.; Ariffin, D. Selection for partial resistance in oil palm progenies to Ganoderma basal stem rot. J. Oil Palm Res. 2004, 16, 12-18.

2. Hushiarian, R.; Yusof, N.A.; Dutse, S.W. Detection and control of Ganoderma boninense: Strategies and perspectives. Springerplus 2013, 2, 555. [CrossRef] [PubMed]

3. Roslan, A.; Idris, A.S. Economic impact of Ganoderma incidence on Malaysian oil palm plantation-A case study in Johor. Oil Palm Ind. Econ. J. 2012, 12, 24-30.

4. Cooper, R.M.; Flood, J.; Rees, R.W. Ganoderma boninense in oil palm plantations: Current thinking on epidemiology, resistance and pathology. Planter 2011, 87, 515-526.

5. Singh, G. Ganoderma-the scourge of oil palms in the coastal areas. Planter 1991, 67, 421-444.

6. Turner, P.D. Oil Palm Diseases and Disorders; Oxford University Press: Oxford, UK, 1981.

7. Idris, A. Basal Stem Rot (BSR) of Oil Palm (Elaeis Guineensis Jacq.) in Malaysia: Factors Associated with Variation in Disease Severity; Wye College, University of London: Wye, UK, 1999.

8. Chung, G.F. Management of Ganoderma diseases in oil palm plantations. Planter 2011, 87, 325-339.

9. Naher, L.; Yusuf, U.K.; Ismail, A.; Tan, S.G.; Mondal, M.M.A. Ecological status of Ganoderma and basal stem rot disease of oil palms (Elaeis guineensis Jacq.). Aust. J. Crop Sci. 2013, 7, 1723-1727.

10. Saldajeno, M.G.B.; Ito, M.; Hyakumachi, M. Interaction between the plant growth-promoting fungus Phoma sp. GS8-2 and the arbuscular mycorrhizal fungus Glomus mosseae: Impact on biocontrol of soil-borne diseases, microbial population, and plant growth. Australas. Plant Pathol. 2012, 41, 271-281. [CrossRef]

11. Fravel, D.R. Commercialization and implementation of biocontrol. Annu. Rev. Phytopathol. 2005, 43, 337-359. [CrossRef]

12. Guetsky, R.; Shtienberg, D.; Elad, Y.; Dinoor, A. Combining biocontrol agents to reduce the variability of biological control. Phytopathology 2001, 91, 621-627. [CrossRef]

13. Haggag, W.M. Improving the biological control of Botryodiplodia disease on some Annona cultivars using single or multi-bioagents in Egypt. Biol. Control 2006, 38, 341-349. [CrossRef] 
14. Roberts, D.P.; Lohrke, S.M.; Meyer, S.L.F.; Buyer, J.S.; Bowers, J.H.; Jacyn Baker, C.; Li, W.; de Souza, J.T.; Lewis, J.A.; Chung, S. Biocontrol agents applied individually and in combination for suppression of soilborne diseases of cucumber. Crop Prot. 2005, 24, 141-155. [CrossRef]

15. Elead, Y.; Köhl, J.; Fokkema, N.J. Control of infection and sporulation of Botrytis cinerea on bean and tomato by saprophytic bacteria and fungi. Eur. J. Plant Pathol. 1994, 100, 315-336. [CrossRef]

16. Fukui, R.; Fukui, H.; Alvarez, A.M. Comparisons of single versus multiple bacterial species on biological control of Anthurium blight. Phytopathology 1999, 89, 366-373. [CrossRef] [PubMed]

17. Guetsky, R.; Shtienberg, D.; Elad, Y.; Fischer, E.; Dinoor, A. Improving biological control by combining biocontrol agents each with several mechanisms of disease suppression. Phytopathology 2002, 92, 976-985. [CrossRef] [PubMed]

18. Guetskyl, R.; Shtienberg, D.; Dinoor, A.; Elad, Y. Establishment, survival and activity of the biocontrol agents Pichia guilermondii and Bacillus mycoides applied as a mixture on strawberry plants. Biocontrol Sci. Technol. 2002, 12, 705-714. [CrossRef]

19. Nusaibah, S.A.; Saad, G.; Tan, G.H. Antagonistic Efficacy of Trichoderma harzianum and Bacillus cereus against Ganoderma Disease of Oil Palm via Dip, Place and Drench (DPD) Artificial Inoculation Technique. Int. J. Agric. Biol. 2017, 19, 299-306. [CrossRef]

20. Sundram, S.; Meon, S.; Seman, I.A.; Othman, R. Symbiotic interaction of endophytic bacteria with arbuscular mycorrhizal fungi and its antagonistic effect on Ganoderma boninense. J. Microbiol. 2011, 49, 551. [CrossRef]

21. Sundram, S.; Meon, S.; Seman, I.A.; Othman, R. Application of arbuscular mycorrhizal fungi with Pseudomonas aeruginosa UPMP3 reduces the development of Ganoderma basal stem rot disease in oil palm seedlings. Mycorrhiza 2015, 25, 387-397. [CrossRef]

22. Wan Zakaria, W.N.F. Screening Potential Biological Control Agents and Efficacy of Mixed-Microorganisms in Controlling Oil Palm Basal Stem Rot Caused by Ganoderma boninense. Master's Thesis, Universiti Malaysia Sarawak (UNIMAS), Kota Samarahan, Malaysia, 2014.

23. Kirschner, R.; Arnold, G.R.W.; Chen, C.-J. Cladobotryum semicirculare sp. nov. (hyphomycetes) from commercially grown Ganoderma tsugae in Taiwan and other Basidiomycota in Cuba. Sydowia 2007, 59, 114-124.

24. Marzuki, N.F.; Goh, Y.K.; Tung, H.J.; Goh, Y.K.; Goh, K.J. Evaluation on the cultural characteristics and antagonistic activities of Cladobotryum semicirculare against Ganoderma boninense in vitro. J. Oil Palm Res. 2015, 27, 326-338.

25. Kang, H.-J.; Sigler, L.; Lee, J.; Gibas, C.F.C.; Yun, S.-H.; Lee, Y.-W. Xylogone ganodermophthora sp. nov., an ascomycetous pathogen causing yellow rot on cultivated mushroom Ganoderma lucidum in Korea. Mycologia 2010, 102, 1167-1184. [CrossRef] [PubMed]

26. Goh, Y.K.; Goh, T.K.; Marzuki, N.F.; Tung, H.J.; Goh, Y.K.; Goh, K.J. Scytalidium parasiticum sp. nov., a new species parasitizing on Ganoderma boninense isolated from oil palm in Peninsular Malaysia. Mycobiology 2015, 43, 107-117. [CrossRef] [PubMed]

27. Agustini, L.; Wahyuno, D.; Indrayadi, H.; Glen, M. In vitro interaction between Phlebiopsis sp. and Ganoderma philippii isolates. Forest Pathol. 2014, 44, 472-476. [CrossRef]

28. Helfer, W. Pilze auf Pilzfruchtkörpern. Libri Botanici 1; IHW-Verlag: Eching, Germany, 1991.

29. Goh, Y.K.; Marzuki, N.F.; Goh, T.K.; Tan, S.Y.; Goh, Y.K.; Goh, K.J. Mycoparasitic Scytalidium parasiticum as a potential biocontrol agent against Ganoderma boninense basal stem rot in oil palm. Biocontrol Sci. Technol. 2016, 26, 1352-1365. [CrossRef]

30. Gohel, V.; Singh, A.; Vimal, M.; Ashwini, P.; Chhatpar, H.S. Bioprospecting and Antifungl Potential of Chitinolytic Microorganisms. Afr. J. Biotechnol. 2006, 5, 54-72.

31. Naraghi, L.; Heydari, A.; Rezaee, S.; Razavi, M. Biocontrol Agent Talaromyces flavus Stimulates the Growth of Cotton and Potato. J. Plant Growth Regul. 2012, 31, 471-477. [CrossRef]

32. Kok, S.M.; Goh, Y.K.; Tung, H.J.; Goh, K.J.; Wong, W.C.; Goh, Y.K. In vitro growth of Ganoderma boninense isolates on novel palm extract medium and virulence on oil palm (Elaeis guineensis) seedlings. Malays. J. Microbiol. 2013, 9, 33-42.

33. Ariffin, D.; Idris, A. A selective medium for the isolation of Ganoderma from diseased tissues. In Proceedings of Proceedings of the International Palm Oil Conference, Progress, Prospects and Challenges Towards the 21st Century (Model 1-Agriculture), Kuala Lumpur Hilton, Malaysia, 9-14 September 1991; Palm Oil Research Institute of Malaysia: Bangi, Malaysia, 1991; pp. 517-519. 
34. Rees, R.W.; Flood, J.; Hasan, Y.; Cooper, R.M. Effects of inoculum potential, shading and soil temperature on root infection of oil palm seedlings by the basal stem rot pathogen Ganoderma boninense. Plant Pathol. 2007, 56, 862-870. [CrossRef]

35. White, T.J.; Bruns, T.D.; Lee, S.B.; Taylor, J.W. Analysis of phylogenetic relationships by amplification and direct sequencing of ribosomal DNA genes. In PCR Protocols: A guide to Methods and Applications; Innis, M.A., Gelfand, D.H., Sninsky, J.J., White, T.J., Eds.; Academic Press: New York, NY, USA, 1990; pp. 315-322.

36. Vujanovic, V.; Goh, Y.K. Sphaerodes mycoparasitica sp. nov., a new biotrophic mycoparasite on Fusarium avenaceum, F. graminearum and F. oxysporum. Mycol. Res. 2009, 113, 1172-1180. [CrossRef]

37. Sokolski, S.; Piché, Y.; Bérubé, J.A. Lophodermium macci sp. nov., a new species on senesced foliage of five-needle pines. Mycologia 2004, 96, 1261-1267. [CrossRef] [PubMed]

38. Yilmaz, N.; Visagie, C.M.; Houbraken, J.; Frisvad, J.C.; Samson, R.A. Polyphasic taxonomy of the genus Talaromyces. Stud. Mycol. 2014, 78, 175-341. [CrossRef] [PubMed]

39. Thompson, J.D.; Higgins, D.G.; Gibson, T.J. CLUSTAL W: Improving the sensitivity of progressive multiple sequence alignment through sequence weighting, position-specific gap penalties and weight matrix choice. Nucleic Acids Res. 1994, 22, 4673-4680. [CrossRef] [PubMed]

40. Tamura, K.; Stecher, G.; Peterson, D.; Filipski, A.; Kumar, S. MEGA6: Molecular Evolutionary Genetics Analysis version 6.0. Mol. Biol. Evol. 2013, 30, 2725-2729. [CrossRef]

41. Corley, R.H.V.; Hardon, J.J.; Tan, G.Y. Analysis of growth of the oil palm (Elaeis guineensis Jacq.). Euphytica 1971, 20, 307-315. [CrossRef]

42. Corley, R.H.V.; Tinker, P.B. The Oil Palm, 5th ed.; Blackwell Publishing: Oxford, UK, 2016.

43. Hardon, J.J.; Williams, C.; Watson, I. Leaf area and yield in the oil palm in Malaya. Exp. Agric. 1969, 5, 25-32. [CrossRef]

44. Goh, Y.K.; Ng, F.W.; Kok, S.M.; Goh, Y.K.; Goh, K.J. Aggressive of Ganoderma boninense isolates on the vegetative growth of oil palm (Elaeis guineensis) seedling at different age. Malays. J. Appl. Biol. 2014, 43, 9-16.

45. Sim, C.C.; Zaharah, A.R.; Tan, M.S.; Goh, K.J. Rapid Determination of Leaf Chlorophyll Concentration, Photosynthetic Activity and NK Concentration of Elaies guineensis Via Correlated SPAD-502 Chlorophyll Index. Asian J. Agric. Res. 2015, 9, 132-138. [CrossRef]

46. Lichtenthaler, H.K.; Buschmann, C. Chlorophylls and Carotenoids: Measurement and Characterization by UV-VIS Spectroscopy. Curr. Protoc. Food Anal. Chem. 2001, 1, F4.3.1-F4.3.8. [CrossRef]

47. Sharifuddin, H.A.H.; Fauziah, I.; Zaharah, A.R. Technique of soil testing and plant analysis and their utilization for crop production in malaysia. Commun. Soil Sci. Plant Anal. 1990, 21, 1959-1978. [CrossRef]

48. Campbell, C.L.; Madden, L.V. Introduction to Plant Disease Epidemiology; John Wiley \& Sons: New York, NY, USA, 1990; p. 532.

49. Sapak, Z.; Meon, S.; Ahmad, Z.M.A. Effect of endophytic bacteria on growth and suppression of Ganoderma infected in oil palm. Int. J. Agric. Biol. 2008, 10, 127-132.

50. Simko, I.; Piepho, H.P. The area under the disease progress stairs: Calculation, advantage, and application. Phytopathology 2012, 102, 381-389. [CrossRef] [PubMed]

51. Wickham, H.; Wickham, M.H. The Ggplot Package. 2007. Available online: https://cran.r-project.org/web/ packages/ggplot2/index.html (accessed on 15 March 2020).

52. RStudio Team. RStudio: Integrated Development for R. Available online: http://www.rstudio.com/ (accessed on 15 March 2020).

53. Schroers, H.-J.; Samuels, G.J.; Seifert, K.A.; Gams, W. Classification of the mycoparasite Gliocladium roseum in Clonostachys as C. rosea, its relationship to Bionectria ochroleuca, and notes on other Gliocladium-like fungi. Mycologia 1999, 91, 365-385. [CrossRef]

54. El-Debaiky, S.A. Antagonistic studies and hyphal interactions of the new antagonist Aspergillus piperis against some phytopathogenic fungi in vitro in comparison with Trichoderma harzianum. Microb. Pathog. 2017, 113, 135-143. [CrossRef]

55. Yang, D.; Plante, F.; Bernier, L.; Piché, Y.; Dessureault, M.; Laflamme, G.; Ouellette, G.B. Evaluation of a fungal antagonist, Phaeotheca dimorphospora, for biological control of tree diseases. Can. J. Bot. 1993, 71, 426-433. [CrossRef]

56. Zalila-Kolsi, I.; Ben Mahmoud, A.; Ali, H.; Sellami, S.; Nasfi, Z.; Tounsi, S.; Jamoussi, K. Antagonist effects of Bacillus spp. strains against Fusarium graminearum for protection of durum wheat (Triticum turgidum L. subsp. durum). Microbiol. Res. 2016, 192, 148-158. [CrossRef] 
57. Costa, L.B.; Rangel, D.E.N.; Morandi, M.A.B.; Bettiol, W. Effects of UV-B radiation on the antagonistic ability of Clonostachys rosea to Botrytis cinerea on strawberry leaves. Biol. Control 2013, 65, 95-100. [CrossRef]

58. Fatema, U.; Broberg, A.; Jensen, D.F.; Karlsson, M.; Dubey, M. Functional analysis of polyketide synthase genes in the biocontrol fungus Clonostachys rosea. Sci. Rep. 2018, 8, 15009. [CrossRef]

59. Mamarabadi, M.; Jensen, D.F.; Lübeck, M. An N-acetyl-beta-D-glucosaminidase gene, cr-nag1, from the biocontrol agent Clonostachys rosea is up-regulated in antagonistic interactions with Fusarium culmorum. Mycol. Res. 2009, 113, 33-43. [CrossRef]

60. Goh, Y.K.; Vujanovic, V. Biotrophic mycoparasitic interactions between Sphaerodes mycoparasitica and phytopathogenic Fusarium species. Biocontrol Sci. Technol. 2010, 20, 891-902. [CrossRef]

61. Kim, S.H.; Vujanovic, V. Changes in mycoparasite-Fusarium hosts interfaces in response to hostile environment as revealed by water contact angle and atomic force microscopy. Biol. Control 2018, 121, 247-255. [CrossRef]

62. Manoch, L.; Dethoup, T. A potential use of Talaromyces species as biological agents against plant pathogenic fungi. Thai J. Agric. Sci. 2011, 44, 81-91.

63. Gao, H.; Zhou, L.; Li, D.; Gu, Q.; Zhu, T.-J. New cytotoxic metabolites from the marine-derived fungus Penicillium sp. ZLN29. Helv. Chim. Acta 2013, 96, 514-519. [CrossRef]

64. Schlingmann, G.; Milne, L.; Carter, G.T. Isolation and identification of antifungal polyesters from the marine fungus Hypoxylon oceanicum LL-15G256. Tetrahedron 2002, 58, 6825-6835. [CrossRef]

65. Breinholt, J.; Jensen, G.W.; Nielsen, R.I.; Olsen, C.E.; Frisvad, J.C. Antifungal macrocyclic polylactones from Penicillium verruculosum. J. Antibiot. 1993, 46, 1101-1108. [CrossRef]

66. Yamagiwa, Y.; Inagaki, Y.; Ichinose, Y.; Toyoda, K.; Hyakumachi, M.; Shiraishi, T. Talaromyces wortmannii FS2 emits $\beta$-caryphyllene, which promotes plant growth and induces resistance. J. Gen. Plant Pathol. 2011, 77, 336-341. [CrossRef]

67. Khalmuratova, I.; Kim, H.; Nam, Y.-J.; Oh, Y.; Jeong, M.-J.; Choi, H.-R.; You, Y.-H.; Choo, Y.-S.; Lee, I.-J.; Shin, J.-H.; et al. Diversity and Plant Growth Promoting Capacity of Endophytic Fungi Associated with Halophytic Plants from the West Coast of Korea. Mycobiology 2015, 43, 373-383. [CrossRef]

68. Johansen, A.; Knudsen, I.M.B.; Binnerup, S.J.; Winding, A.; Johansen, J.E.; Jensen, L.E.; Andersen, K.S.; Svenning, M.M.; Bonde, T.A. Non-target effects of the microbial control agents Pseudomonas fluorescens DR54 and Clonostachys rosea IK726 in soils cropped with barley followed by sugar beet: A greenhouse assessment. Soil Biol. Biochem. 2005, 37, 2225-2239. [CrossRef]

69. Sutton, J.C.; Liu, W.; Ma, J.; Brown, W.G.; Stewart, J.F.; Walker, G.D. Evaluation of the Fungal Endophyte Clonostachys Rosea as an Inoculant to Enhance Growth, Fitness and Productivity of Crop Plants. Acta Hortic. 2008, 782, 279-286. [CrossRef]

70. Maity, A.; Pal, R.K.; Chandra, R.; Singh, N.V. Penicillium pinophilum-A novel microorganism for nutrient management in pomegranate (Punica granatum L.). Sci. Hortic. 2014, 169, 111-117. [CrossRef]

71. Silitonga, N.; Sembiring, M.; Marbun, P.; Rosneli. Application of phosphate solubilizing fungi and various sources of P-Fertilizers toward P-Available and P Nutrient content of soybean (Glycine max L. Merrill) in andisol soil. IOP Conf. Ser. Earth Environ. Sci. 2019, 260, 012159. [CrossRef]

72. Kamou, N.N.; Cazorla, F.; Kandylas, G.; Lagopodi, A.L. Induction of defense-related genes in tomato plants after treatments with the biocontrol agents Pseudomonas chlororaphis ToZa7 and Clonostachys rosea IK726. Arch. Microbiol. 2020, 202, 257-267. [CrossRef] [PubMed]

73. Mouekouba, L.D.O.; Zhang, L.; Guan, X.; Chen, X.; Chen, H.; Zhang, J.; Zhang, J.; Li, J.; Yang, Y.; Wang, A. Analysis of Clonostachys rosea-Induced Resistance to Tomato Gray Mold Disease in Tomato Leaves. PLoS ONE 2014, 9, e102690. [CrossRef] [PubMed]

74. de Boer, M.; Bom, P.; Kindt, F.; Keurentjes, J.J.B.; van der Sluis, I.; van Loon, L.C.; Bakker, P.A.H.M. Control of Fusarium wilt of radish by combining Pseudomonas putida strains that have different disease-suppressive mechanisms. Phytopathology 2003, 93, 626-632. [CrossRef] [PubMed]

75. Döring, T.F.; Pautasso, M.; Finckh, M.R.; Wolfe, M.S. Concepts of plant health—Reviewing and challenging the foundations of plant protection. Plant Pathol. 2012, 61,1-15. [CrossRef]

(C) 2020 by the authors. Licensee MDPI, Basel, Switzerland. This article is an open access article distributed under the terms and conditions of the Creative Commons Attribution (CC BY) license (http://creativecommons.org/licenses/by/4.0/). 